\title{
Medium term effects of culture, transactions and institutions on opportunity entrepreneurship
}

\author{
Panagiotis E Petrakis ${ }^{*}$ and Pantelis C Kostis
}

\author{
* Correspondence: \\ ppetrak@econ.uoa.gr \\ Economic Department, National \\ and Kapodistrian University of \\ Athens, 5 Stadiou Street, Athens PC \\ 10562, Greece
}

\begin{abstract}
Cultural evolution is a long-term endogenous process which is revealed in society's cultural traits and it is embodied in institutional characteristics (property rights protection, rule of law, etc.) and transaction characteristics (risk levels, time required for start-ups, corruption levels, literacy levels, etc.). In the short- and medium-term, culture, institutions and transactions are exogenous for the economic and societal system. The paper aims to explore the roles of cultural, transaction and institution characteristics in the determination of opportunity entrepreneurship, at the medium-term. A series of variables is used to express these roles, which are analysed with a principal component analysis and a regression analysis. As expected, the conclusions confirm that the cultural traits both positively and negatively affect opportunity entrepreneurship depending on the particular traits combination. Moreover, the effect of enhanced transaction characteristics and economic institutions is conducive to opportunity entrepreneurship. Performing a sensitivity analysis, we construct a hypothetical, more opportunity entrepreneurship-oriented world by postulating pro-entrepreneurship cultural traits. In this 'new world', because cultural traits are no longer an issue, they present 'entrepreneurial maturity'; the important factors in promoting opportunity entrepreneurship are transaction and economic institution characteristics.
\end{abstract}

JEL codes: D23, L14, L26, M13, P14

Keywords: Opportunity entrepreneurship; Culture; Transactions; Institutions; Endogeneity

\section{Background}

The concept of opportunity entrepreneurship raises researchers' interest and can be found even in the early entrepreneurial contributions of Schumpeter $(1934,1950)$ and Knight (1971) and in the later contributions of Shane and Venkataraman (2000) and Audretsch (2007).

As Acemoglu (2009) remarks, references to the general circumstances of the environment that possibly have an impact on attitude, human conventions and culture can be found in de Montesquieu (1989), Machiavelli (1987) and Marshall (1997). Culture and economics can be seen as two of the more powerful forces shaping human behaviour (Throsby 2001) and thus economic activity. Recently, Spolaore and Wacziarg (2013) argue that that economic development is affected by traits that have been transmitted across generations, through fundamental factors, rooted in long-term history. Furthermore, a widespread interpretation is that current economic performance is 
shaped through history via 'institutions'. Acemoglu et al. (2001) argue that colonial origin is correlated with indicators of the quality of current institutions, e.g. institutions protecting property rights from the abuse of governments.

The aim of the paper is to analyse opportunity entrepreneurship based on determining factors that originate from three fields: cultural traits, transaction characteristic, and economic institution characteristics. Each group is represented by a set of related variables. More specifically, the focus is on two main influence groups for entrepreneurial capital (culture, and transactions and institutions) in an economy. Even though we intuitively comprehend their importance, quantifying and formally analysing them can prove challenging. These factors are not separate or isolated in their structural effects on opportunity entrepreneurship. Therefore, the present paper also contributes to entrepreneurship theory by identifying the opportunity entrepreneurship determination framework. Furthermore, it improves the art of designing a different, more opportunity entrepreneurship-oriented world by postulating improved human behaviours and then analysing the effects observed.

The order of the paper is as follows. 'The theoretical background' section presents the theoretical work on entrepreneurship in general and, specifically, on opportunity entrepreneurship, the cultural traits, transaction characteristics and economic institutions characteristic, and describes the variables used. 'The methodology employed' section describes the methodology employed, i.e. the empirical model and measurements, while 'Empirical results and discussion' section presents the empirical work and the discussion of the results. Finally, 'Conclusions' presents the conclusions.

\section{The theoretical background}

The following are presented four basic points in the theoretical background of the present paper, regarding the interrelationships between the terms that are analysed. (a) Cultural traits are a reflection of cultural evolution which is a long-term endogenous process. (b) Cultural evolution is embodied in institution settings and transactions characteristics of the economies. (c) Opportunity entrepreneurship (where to discover opportunities theories) is a by-product of cultural traits, institution settings and transaction characteristics. Their influence is exercised by their portfolio consistency of interactions and their levels of operation. (d) In the medium- (and short-) term, cultural traits, institution settings and transaction characteristics are exogenous to opportunity entrepreneurship.

\section{Cultural traits are a reflection of cultural evolution which is a long-term endogenous process}

Cultural evolution is a set of processes (Richerson and Boyd 2005), and the cultural transmission process centrally involves psychology and communication. The cultural traits of societies reflect psychological social stereotypes that have been created over time and are prior human constructs to the current transactions and institutions (Petrakis and Kostis 2013a). People are influenced by norms, and hence the more frequent a variant is, the more likely it is to be adopted (Rozin 2010). People growing up in different societies exhibit measurably different ways of thinking and behaving due to different cultural norms and beliefs acquired from other members of their societies (Mesoudi 2011). Actually, 
culture can be defined as a product made by the significant contribution of human cognition and motivations, interpersonal interactions and communication and differences in ecology and geography across the earth (Conway and Schaller 2007).

However, it should be noted though that individuals are not passive receivers of their cultural environment. They use cultural background as a tool to understand their experiences (Hong 2009). Thus, any matching of geographical boundaries and uniqueness in cultural background characteristics cannot be accepted, as this would reduce the likelihood of the appearance of the same syndromes at the same periods of time in different societies. Cultural syndromes constitute a link between the distant factors that created such syndromes and today's cultural conditions.

Spolaore and Wacziarg (2013) discuss different channels through which intergenerationally transmitted characteristics may impact economic development culturally and biologically via behavioural or symbolic transmission. They examine the very long-run effects of geographic, historical, cultural and institutional factors on productivity and per capita income, through reviewing the new literature on these relationships, and present empirical evidence documenting such effects. They point that the evidence suggests that economic development is affected by traits that have been transmitted across generations over the very long run.

Individuals have a storage room fulfilled with information and data due to the existence of a cultural and institutional background in the societies they live. These two kinds of background are deeply rooted in the subconscious and the environment of individuals and are responsible for shaping human behaviour to deal with various aspects of daily life. Their shaping is essentially based on the historical and cultural heritage of each nation. Individuals are able to use these elements in order to structure their cognitive background or their reasoning processes (Douglas 1987). In this way, the cultural and institutional background offers a series of habits and rules that the individual can use as a standard to check whether they have identified the best solution or to identify which existing solution is the best according to the standards set by their cultural and institutional background (Hodgson 1988).

\section{Cultural evolution is embodied in institution settings and transaction characteristics}

As pointed by North (1990), institutions can be divided in formal and informal. Mental models, such as culture, determine the way information is managed by individuals and the criteria through which decisions are made.

There are some first-, second- and third-round effects regarding the relationship between cultural traits and institutions. As first-round effects can be seen the influences of the cultural traits on the operations of political institutions. As second-round effects can be seen the fact that political institutions shape economic institutions, which then create incentives. Aside from this indirect effect between cultural traits and economic institutions, the secondary elements of economic institutions are also directly influenced by cultural traits; the extent to which the goal setting of a society is linked to the per capita product, income or its happiness, depends on its culture. Economic institutions, in the form of property rights and contractualization, are influenced by the characteristics of trade and the cultural stereotypes (Boyer and Petersen 2012). Lastly, as third-round effects, the distribution of wealth and the extent of economic growth are shaped by economic institutions. 
There is also a significant relationship between cultural traits and the transaction cost of the economies, which can be considered as an important extension of the transaction cost theory. Cultural background is a determinant of consumer behaviour (Cleveland and Laroche 2007) and of social structures in economic relationships (Greif 1994). When choosing a strategy for the international expansion of activities and transactions, the study of this relationship is particularly important. Shane (1992) tried to make a connection between the differences in the cultural background among societies and the perceptions on transaction costs observed and the differences in societies' preferences for licensing and international joint ventures. There is a remarkable literature that focuses on the role of cultural differences in creating intercultural uncertainty which has a direct effect on transaction costs (intercultural communications and trade) (Jonsson 2001).

According to Chen et al. (2002), not collectivist cultures display more opportunistic behaviour in transactions within the same group compared with collectivist cultures which display greater opportunistic behaviour in transactions with other groups. Furthermore, there can be a connection between cultural traits and the choices made in transactions. Firstly, regarding the 'uncertainty avoidance' cultural trait, Hofstede (1980) concludes that lower scores result to more easy interactions with strangers. He also states that in societies where individualism and collectivism co-exist, the transaction value is low (in-group transactions) and when either individualism or collectivism is dominant, the transaction value is relatively high. Lastly, Petrakis and Valsamis (2013) argue that the cultural traits that promote economic growth reduce the transaction costs and enhance economic institutions, while the cultural traits that promote the social characteristics of a society increase transaction costs.

\section{Opportunity entrepreneurship as a by-product of cultural traits, institution settings and transaction characteristics}

The influence of cultural traits, institution settings and transaction characteristics on opportunity entrepreneurship is exercised by their portfolio consistency of interactions and their levels of operation.

An important part of the entrepreneurial process is the identification and the exploitation of entrepreneurial opportunities. There have been considered three basic schools of thought for the identification of entrepreneurial opportunities (Companys and McMullen 2007): (a) the 'Economic School' in which an entrepreneurial opportunity is defined as an objective phenomenon that exists in time and space and may be unknown to some people (Shane 2003; Shane and Venkataraman 2000), (b) the 'School of Culture', which supports that entrepreneurial opportunities are subjective and not objective constructionsphenomena (Sarasvathy et al. 2003) and finally, (c) the 'Sociopolitical School' which supports the important role administrative mechanisms play in the definition of entrepreneurial opportunities (Granovetter 1985). It seems that two key factors seem to play a role first in the identification of entrepreneurial opportunities and then in their activation as entrepreneurship events: knowledge levels (Marsili 2002; Mueller 2007; Acs et al. 2008; Acs et al. 2009) and the cultural background of the societies (Petrakis and Kostis 2013b).

Chen et al. (2002) try to identify which factors shape opportunistic behaviours, mainly concentrating to the role of culture and more specifically on the role of individualism/collectivism and the moral barriers. Salamouris (2013) points that overconfidence matters for 
entrepreneurship but overconfidence is affected by the perceptions about the cultural value of uncertainty. Pinillos and Reyes (2011) argue that a country's entrepreneurship rate is negatively related to individualism when development is medium or low and positively related to individualism when the level of development is high. Culture contributes to the emergence of entrepreneurial activity (Tominc and Rebernik 2007; Kreiser et al. 2013). Thus, entrepreneurship is different among countries or for different time periods because societies have embraced it to various degrees (Reynolds et al. 2002; Freytag and Thurik 2007). Stuetzer et al. (2013) argue that knowledge creation, the economic context and an entrepreneurial culture have an indirect effect on the individual perception of founding opportunities, which in turn predict the start-up intentions and activity. However, Ghoshal and Moran (1996) point that despite the opportunistic propensity of an individual, he will not act opportunistically in all transactions. More recently, Uzunidis et al. (2014) point that entrepreneurial function relies on the individual characteristics of the entrepreneur and the importance of the social, economic and political environment. Furthermore, in-group collectivism, which is highly represented through strong family ties, matters on the size of entrepreneurial activities (Del Giudice et al. 2013; Lingas 2013).

Furthermore, the role of institutions is crucial for entrepreneurship (Karlsson and Acs 2002; Karlsson and Karlsson 2002; Acs et al. 2008). Institutions, resources and history, among other factors, determine the success of an entrepreneurial activity (Baumol Baumol 1990). Entrepreneurial opportunities and the starting up of businesses, in order to exit, require clear institutional and legal environment, the smooth operation of the markets under specific rules, privatisation and collectivization (Wennekers et al. 2002).

If steps are taken to apply policy measures which support entrepreneurship in the fields of financing and entrepreneurial abilities, then we can expect to see more numerous and more vigorous entrepreneurial events, with positive consequences for the process of economic development (Petrakis 1997, 2004).

\section{The long-term endogeneity and the medium- and short-term exogeneity}

If we accept that entrepreneurship also requires suitable institutions and a specific environmental background, the basic question raised is why countries with ineffective institutions do not 'copy' the institutions of developed countries (Fukuyama 2001). The answer lies on the fact that institutions do not change easily; it takes 10 to 100 years for formal institutions and 100 to 1,000 years for informal in order to be changed. Informal institutions are human creations based on the values, ideas and perceptions of their creators. Thus, any changes are limited.

Moreover, the social stereotypes forming the cultural traits may be characterised as long lasting, as the forces that have shaped the construction of the stereotypes are considered exogenous (e.g. climate and environment) (Schwatrz 2009). Thus, cultural values present stability through time. In general, cultural stereotypes present a great resistance towards change and to their own redefinition (Johnston 1996).

However, under certain and strong shocks (a war, a great recession, etc.), cultural background may change, but institutions and transaction characteristics will still remain unchanged even after such a shock. This is what the present paper investigates through the sensitivity analysis (see 'Empirical results and discussion' section). In such cases, institutions and transaction characteristics are affected in the long run and in an indirect way 
through the cultural traits that are embodied in these. The embodying procedure is a long-term evolution process. Therefore, in the short- and the medium-term horizon, there are not any possible observed interconnections between the three groups of variables.

According to Spulber (2008), the economic equilibrium, including the structure of transactions, prices and allocation of goods, depends on the entrepreneurs' actions. Entrepreneurs will be successful in establishing firms only if firms provide transaction benefits that cannot be achieved by consumer organisations. Similarly, societies with already developed entrepreneurship levels may lead to the cultural trait formation of their members, e.g. by creating members with a greater assertiveness and performanceoriented characteristics. Thus, is it cultural traits, transaction characteristics and economic institutions that influence entrepreneurship, or does entrepreneurship itself affect them? The previous question and concern creates a need to check for the endogeneity problem between opportunity entrepreneurship and these variables.

Perhaps there is a two-way effect between entrepreneurship and institutions (and culture and transactions as well) in the long run. However, in the medium-term or the short-term these are exogenous to entrepreneurship (as will see in the empirical results).

\section{Hypotheses testing}

Based on the definitions of the variables used to express cultural traits by House et al. (2004), we can assume that societies with high values for performance orientation (see definition in Table 1) should be associated with higher opportunity entrepreneurship levels, given that they promote profit and performance improvement in their economies. Such societies value training, development, assertiveness, competitiveness, individual achievement and taking initiative, and opportunity entrepreneurship contributes towards these goals. High values for future orientation (see definition in Table 1) should be related to increases in opportunity entrepreneurship too. Indeed, such societies tend to achieve economic success, have flexible and adaptive organisations and managers and favour financial prosperity, which can facilitate new businesses. Furthermore, a decrease in gender egalitarianism (see definition in Table 1) differences should reflect greater opportunity entrepreneurship because more women will have the chance to exercise their entrepreneurial skills. Such societies tend to afford women a greater role in community decision-making and have a higher percentage of women participating in the labour force and in positions of authority. Moreover, it is expected that a positive correlation exists between higher values of assertiveness (see definition in Table 1) and opportunity entrepreneurship given that aggression and austerity drive global competitiveness. Such societies value success, progress and competition and tend to act and think of others as opportunistic. Generally, collective activity in a society (institutional collectivism - see definition in Table 1) should be positively related to opportunity entrepreneurship, as group loyalty is encouraged even if individual goals suffer. In contrast, in-group collectivism (see definition in Table 1) is expected to be associated with lower levels of opportunity entrepreneurship because, in essence, in-group collectivism is incompatible with competitiveness and the development of free entrepreneurship (with no obstacles): it favours conceptualism and small, low-risk businesses. High levels of power distance (see definition in Table 1) indicate that economic development occurs only for those who (mainly) have economic 
Table 1 Definition of variables and data sources ${ }^{a}$

\begin{tabular}{|c|c|c|c|}
\hline & Variables & Definition & Source of elements \\
\hline $\mathrm{OPP}$ & $\begin{array}{l}\text { Opportunity } \\
\text { entrepreneurship }\end{array}$ & $\begin{array}{l}\text { It is the dependent variable. The percentage of 18- } \\
64 \text {-year-olds who are either nascent entrepreneurs or } \\
\text { owner-managers of new businesses, who (1) claim to } \\
\text { be driven by opportunity rather than necessity and } \\
\text { (2) indicate that the main driver for their involvement } \\
\text { is independence or increasing, rather than maintaining } \\
\text { their income. Mean for the period 2001-2006 }\end{array}$ & $\begin{array}{l}\text { Global Entrepreneurship } \\
\text { Monitor (GEM) }\end{array}$ \\
\hline \multirow[t]{9}{*}{$\begin{array}{l}C_{1}, C_{2} \\
\text { and } C_{3}\end{array}$} & $\begin{array}{l}\text { Performance } \\
\text { orientation }\end{array}$ & $\begin{array}{l}\text { The degree to which a society encourages and } \\
\text { rewards its members for performance improvement } \\
\text { and excellence }\end{array}$ & $\begin{array}{l}\text { House et al. (2004) (the data } \\
\text { were collected in the period } \\
\text { 1995-1997) }\end{array}$ \\
\hline & $\begin{array}{l}\text { Future } \\
\text { orientation }\end{array}$ & $\begin{array}{l}\text { The extent to which individuals engage in future- } \\
\text { oriented behaviours, such as delaying gratification, } \\
\text { planning and investing in the future }\end{array}$ & \\
\hline & $\begin{array}{l}\text { Gender } \\
\text { egalitarianism }\end{array}$ & $\begin{array}{l}\text { The degree to which a society minimises gender } \\
\text { inequality }\end{array}$ & \\
\hline & Assertiveness & $\begin{array}{l}\text { The degree to which individuals are assertive, } \\
\text { confrontational and aggressive in their relationships } \\
\text { with others }\end{array}$ & \\
\hline & $\begin{array}{l}\text { Institutional } \\
\text { collectivism }\end{array}$ & $\begin{array}{l}\text { The degree to which organisational and societal } \\
\text { practices encourage and reward collective } \\
\text { distribution of resources and collective action }\end{array}$ & \\
\hline & $\begin{array}{l}\text { In-group } \\
\text { collectivism }\end{array}$ & $\begin{array}{l}\text { The degree to which individuals express pride, } \\
\text { loyalty and cohesiveness in their organisations } \\
\text { or families }\end{array}$ & \\
\hline & Power distance & $\begin{array}{l}\text { The degree to which members of a society expect } \\
\text { power to be distributed equally }\end{array}$ & \\
\hline & $\begin{array}{l}\text { Human } \\
\text { orientation }\end{array}$ & $\begin{array}{l}\text { The degree to which a society encourages and } \\
\text { rewards individuals for being fair, altruistic, generous, } \\
\text { caring and kind to others }\end{array}$ & \\
\hline & $\begin{array}{l}\text { Uncertainty } \\
\text { avoidance }\end{array}$ & $\begin{array}{l}\text { The extent to which members of an organisation or } \\
\text { society strive to avoid uncertainty by reliance on } \\
\text { social norms, rituals and bureaucratic practices to } \\
\text { alleviate the unpredictability of future events }\end{array}$ & \\
\hline \multirow[t]{6}{*}{$\mathrm{Tl}$} & Composite risk & $\begin{array}{l}\text { This is the weighted average of individual risk } \\
\text { indicators (political, financial and economic risk). The } \\
\text { larger the value, the lower the level of risk for the } \\
\text { country. It is the mean for the period of 1995-2005 }\end{array}$ & PRS Group (ICRG database) \\
\hline & $\begin{array}{l}\text { Starting a } \\
\text { business }\end{array}$ & $\begin{array}{l}\text { Time is recorded in calendar days. This measure } \\
\text { captures the median duration that incorporation } \\
\text { lawyers indicate is necessary to complete a procedure } \\
\text { with a minimum follow-up with government agencies } \\
\text { and no extra payments. It is the mean for the } \\
\text { period of 2004-2005 }\end{array}$ & $\begin{array}{l}\text { Doing business reports, } \\
\text { The World Bank Groups }\end{array}$ \\
\hline & $\begin{array}{l}\text { Corruption } \\
\text { perceptions } \\
\text { index }\end{array}$ & $\begin{array}{l}\text { Is a snapshot of perceptions of public sector } \\
\text { corruption. It uses the counter-variable, so the values } \\
\text { it can assume are between } 0 \text { (highly clean) and } 10 \\
\text { (highly corrupt). It is the mean for the period of } \\
\text { 2001-2005 }\end{array}$ & Transparency International \\
\hline & Literacy rate & $\begin{array}{l}\text { The ability to read and write as a percentage of } \\
\text { total population (data period 1995-2005) }\end{array}$ & $\begin{array}{l}\text { UNESCO Institute for } \\
\text { Statistics }\end{array}$ \\
\hline & Property rights & $\begin{array}{l}\text { An assessment of the ability of individuals to } \\
\text { accumulate private property, secured by clear laws } \\
\text { that are fully enforced by the state. It is the mean for } \\
\text { the period of 1996-2005 }\end{array}$ & $\begin{array}{l}\text { The Heritage Foundation, } \\
\text { Index of Economic } \\
\text { Freedom (HER) }\end{array}$ \\
\hline & Rule of law & $\begin{array}{l}\text { Measures the extent to which stakeholders have } \\
\text { confidence in and abide by the rules of society. In } \\
\text { particular, it focuses on the quality of contract } \\
\text { enforcement, the police and the courts, as well as the } \\
\text { likelihood of crime and violence. It is the mean for } \\
\text { the period of 1996-2005 }\end{array}$ & $\begin{array}{l}\text { Business Environment } \\
\text { Risk Intelligence (BRI), }\end{array}$ \\
\hline
\end{tabular}


Table 1 Definition of variables and data sources $^{a}$ (Continued)

\begin{tabular}{llll}
\hline BIRTH & Birth rate & $\begin{array}{l}\text { The number of childbirths per 1,000 people per year } \\
\text { (2009 data) }\end{array}$ & CIA World Factbook \\
PAT & Patents & $\begin{array}{l}\text { Total number patents applied by a country in a year } \\
\text { (2008 data) }\end{array}$ & $\begin{array}{l}\text { Global Innovation Index } \\
\text { 2009-2010 }\end{array}$ \\
\hline
\end{tabular}

power in societies. Consequently, it is expected to have a negative correlation with opportunity entrepreneurship. In such societies, only a few people have access to resources, skills and capabilities. Human orientation (see definition in Table 1) is expected to have a positive correlation with opportunity entrepreneurship because, in societies with a high level of human orientation and that have the primary aim being profits, the government's focus should be on individuals. There is expected to be a negative correlation between uncertainty avoidance (see definition in Table 1) and opportunity entrepreneurship because lower levels of uncertainty avoidance have been repeatedly associated with higher levels of economic activity (Swierczek and Ha 2003; Hofstede et al. 2010). Such societies tend to be less calculating when taking risks and show less resistance to change.

All cultural traits dimensions of the societies positively affect opportunity entrepreneurship levels, except from in-group collectivism, power distance and uncertainty avoidance that seem to have a negative effect.

Based on the definitions of the variables used in this paper to express transaction costs, we can assume that the high levels of composite risk are positively related to increases in opportunity entrepreneurship. Composite risk is used as a proxy of economic uncertainty in the economy because an increase (i.e. decrease in risk) is correlated with higher levels of opportunity entrepreneurship. In addition, uncertainty has a more prominent role in the entrepreneurial economy because the knowledge capital is inherently less certain than physical capital (Audretsch 2007). When more time is necessary to start a business, opportunity entrepreneurship may be inhibited. Furthermore, the relationship between the levels of corruption, as expressed by the corruption perceptions index variable, and the opportunity entrepreneurship is also expected to be negative. Corruption adds an element of unpredictability in the economies. When an economy is in high corruption, it is hard to understand whether you will be penalised or not. In such an environment, entrepreneurs might be deterred from starting companies if they do not know when or if they will be punished for being successful. Furthermore, high corruption can also distort incentives and cause general misallocation of resources in a society. Lastly, it is expected that the greater a population's literacy rate, the more rational the decision-making and promotion of opportunity entrepreneurship will be.

Higher levels of transaction costs, as expressed through high composite risk, much time to start a business, high levels of corruption and low levels of literacy rates, inhibit opportunity entrepreneurship levels.

A high value for the property rights variable indicates that a country's laws protect private property rights, the government enforces those laws, the judiciary is 
independent, there is no corruption and it is easy to enforce contracts. These conditions are expected to facilitate opportunity entrepreneurship and encourage the new businesses foundation. For the same reason, high values for the rule of law variable are expected to have a positive correlation with opportunity entrepreneurship.

Well organised economic institutions, as expressed through high property rights protection and high sentiment of rule of law in societies, enhance opportunity entrepreneurship levels.

Table 2 indicates the overall relationships expected between the variables used in this paper as independent (cultural traits, transaction characteristics and economic institutions characteristics) and dependent (opportunity entrepreneurship), which is based on various studies in the literature and the definitions of the variables.

\section{The data}

In collecting the data, we treat the world as a typical country, assuming that the production process is homogenous around the world because we do not allow for heterogeneous growth experiences (Bos et al. 2010). Our limited degrees of freedom (small sample of observations we have available due to our limited number of observations for entrepreneurial variables) does not permit us to deepen our analysis in this respect. Variables are precisely defined in Table 1. Sample statistics are given in Table 3.

The data for the dependent variable (OPP) concern the mean performance of each country for the time period of 2001-2006. For the variables expressing cultural traits, the reference period is 1995-1997. There has not been a more recent organised effort to measure the cultural traits in so many countries. For the period analysed, the variables related to the cultural traits may be regarded as remained unchanged. For the variables where this was possible, the data refer to a mean value for the decade of 1995-2005 and 1996-2005, while for the rest, we ensured that they covered at least

Table 2 Relationship of variables to the dependent variable

\begin{tabular}{lll} 
& Opportunity entrepreneurship \\
\hline Performance orientation & + & + \\
Future orientation & + & + \\
Gender egalitarianism & - \\
Assertiveness & - \\
Institutional collectivism & + \\
In-group collectivism & - \\
Power distance & + \\
Human orientation & - \\
Uncertainty avoidance & - \\
Composite risk & + \\
Starting a business & + \\
Corruption perception index & + \\
Literacy rate & + \\
Property rights & \\
Rule of law &
\end{tabular}


Table 3 Descprictive statistics ${ }^{a}$

\begin{tabular}{lllllll}
\hline Variables/Statistics & N & Median & Mean & St. Dev. & Min & Max \\
\hline Opportunity entrepreneurship & 42 & 4.185 & 4.121 & 0.41 & 3.20 & 4.90 \\
Performance orientation & 42 & 3.915 & 3.873 & 0.52 & 2.85 & 5.07 \\
Future orientation & 42 & 3.433 & 3.423 & 0.35 & 2.50 & 4.08 \\
Gender egalitarianism & 42 & 4.110 & 4.111 & 0.35 & 3.38 & 4.79 \\
Assertiveness & 42 & 4.295 & 4.294 & 0.46 & 3.25 & 5.22 \\
Institutional collectivism & 42 & 5.295 & 5.035 & 0.76 & 3.53 & 6.36 \\
In-group collectivism & 42 & 5.180 & 5.158 & 0.39 & 3.89 & 5.64 \\
Power distance & 42 & 3.950 & 4.038 & 0.47 & 3.29 & 5.12 \\
Human orientation & 42 & 4.160 & 4.215 & 0.63 & 2.88 & 5.32 \\
Uncertainty avoidance & 42 & 79.226 & 76.730 & 8.70 & 58.18 & 89.29 \\
Composite risk & 42 & 32.000 & 43.583 & 39.30 & 2.00 & 159.50 \\
Starting a business & 42 & 4.107 & 4.104 & 2.48 & 0.34 & 7.91 \\
Corruption perceptions index & 41 & 98.900 & 95.717 & 5.82 & 66.00 & 99.70 \\
Literacy rate & 42 & 63.636 & 62.996 & 20.77 & 10.00 & 90.00 \\
Property rights & 42 & 0.615 & 0.638 & 0.22 & 0.27 & 0.95 \\
Rule of law & 41 & 1.360 & 2.086 & 1.54 & 1.00 & 7.00 \\
Birth rate & 42 & 10.875 & 13.489 & 5.05 & 7.42 & 26.01 \\
Patents & 42 & 4.185 & 4.121 & 0.41 & 3.20 & 4.90 \\
\hline
\end{tabular}

${ }^{\mathrm{a}}$ The 42 countries in the sample constitute $90.44 \%$ of global GDP in 2007 (IMF Database). The countries are: Argentina, Australia, Austria, Brazil, Canada, China, Colombia, Denmark, Ecuador, Finland, France, Germany, Greece, Hong Kong, Hungary, India, Indonesia, Ireland, Israel, Italy, Japan, Malaysia, Mexico, Netherlands, New Zealand, Philippines, Poland, Portugal, the Russian Federation, Singapore, Slovenia, South Africa, South Korea, Spain, Sweden, Switzerland, Taiwan, Thailand, Turkey, the United Kingdom, USA, and Venezuela.

two or more years of the period of 2001-2006. The birth rate variable is from the year 2009 but is long lasting and does not change easily. The number of patents is from the year 2008.

\section{The methodology employed}

The basic model that will be examined is the following:

$$
\mathrm{OPP}_{i}=\beta_{0}+\beta_{1} \times C_{i}+\beta_{2} \times \mathrm{TI}_{i}+\varepsilon_{i}
$$

where the dependent variable is opportunity entrepreneurship, $C_{i}$ represents the variables expressing cultural traits and $T I_{i}$ represents the variables expressing transaction characteristics and economic institutions characteristics. The subscript $i$ refers to the countries used. Through this model, we aim to investigate whether the three hypotheses presented are satisfied or not.

In order to abstract from the complexity of the explanatory variables, we use the principal component analysis (PCA). It is used when there is redundancy in the variables used because they are measuring the same construct and so they are correlated with one another. Smith (2002) comments that PCA is a way of identifying patterns in data and expressing the data in such a way as to highlight their similarities and differences. It is used to reduce complex data in order to reveal the sometimes hidden, simplified structures that often underlie it (Shlens 2009). More specifically, it is a factor extraction method used to form uncorrelated linear combinations of the observed variables, which is then used to obtain the initial factor solution, when a correlation matrix 
is singular. It keeps the most important information from the data table, simplifying the description of the dataset and analysing the structure of the variables (Abdi and Williams 2010). Such an analysis allows us to reduce the number of variables representing cultural traits, transaction characteristics and economic institutions characteristics while detecting the structure in the relationships between these variables.

Through the PCA, a number of principal components (PC) emerge as a linear combination of optimally weighted variables. This process overcomes the problem of redundancy because the observed variables are reduced into artificial variables (principal components) much smaller in number. The first PC accounts for a maximal amount of total variance, while the amount of variance that was not accounted for, is accounted by the second PC. Thus, the second PC is correlated with variables that did not correlated strongly with the first one. Successive components explain progressively smaller amounts of variance. After the PCA, the PCs display varying degrees of correlation with the variables used but are completely uncorrelated with one another (zero correlation).

There are two groups of variables for which PCA is applied. The first is the variables expressing the cultural traits, and the other is the variables expressing transaction characteristics and economic institutions characteristics. The effect of the PCs on opportunity entrepreneurship is examined using a linear regression created by the ordinary least squares method (OLS), as in the model presented above. In a linear regression, we use the principal components with the greatest variances (initial eigenvalues $>1$ ).

In order to check for endogeneity between the variables used, we use the version of the Hausman test (Hausman 1978) proposed by Davidson and MacKinnon (1989, 1993), which tests for exogeneity by running an auxiliary regression. The null hypothesis states that the model yields consistent estimates, while the reported $p$ values state the probability that the test statistic is zero, which would imply the acceptance of the null hypothesis. In this test, we use a set of instrumental variables that are correlated with the 'suspect' variable but are not correlated with the error term of the regression that has opportunity entrepreneurship as a dependent variable. Only if endogeneity is not present will the OLS estimates be consistent and not biased. Furthermore, the different partial instrumental variables $R^{2}$ are reported in order to describe how much of the squared residuals are explained by the instrumental variables. The partial $p$ value, which is the probability that the $F$ value for each instrumental variable is zero, is also reported. Both tests describe how good (strong) the instrumental variables are in explaining opportunity entrepreneurship.

Furthermore, a sensitivity analysis on this basic scenario is also included. In this case, we tried to create a more opportunity entrepreneurship-oriented world through increasing or decreasing the values of some variables expressing the cultural traits. The scope of this experiment is to create a more opportunity entrepreneurship-oriented world, where the culture characteristics that promote opportunity entrepreneurship are enhanced, resulting in the population being more performance- and future-oriented, and more competitive, as expressed by greater institutional collectivism and implementing more risky practices. The goal is to observe the impact of cultural traits, transaction characteristics and economic institutions characteristics on shaping opportunity entrepreneurship under these changing circumstances in societies. The selection of the variables improved or weakened for this sensitivity analysis was based on how 
important these variables are in the formation of PCs (see Table 4). Thus, the values of performance orientation, future orientation, assertiveness, and institutional collectivism variables are increased by $30 \%$, and the values of uncertainty avoidance variable are decreased by $30 \%$ for the countries scoring below the average in each variable, respectively.

In order to reach these goals (and apart from the description of the new findings), a structural change check is performed relating the alternative world to the basic scenario. In effect, we constructed two groups of 42 observations. These two groups make a new variable for each of the variables used. The first (group 1) concerns the variable's values in the basic scenario, and the second (group 2) concerns the variable's values in the case of a more opportunity entrepreneurship-oriented world. The estimates concerning the statistical importance of new factors that are created led us to some conclusions regarding the new configuration conditions for opportunity entrepreneurship.

\section{Empirical results and discussion}

In terms of cultural traits, three PCs were determined $\left(C_{1}, C_{2}\right.$ and $C_{3}$ in Table 4$)$ that explain $37.86 \%, 20.24 \%$ and $14.86 \%$ of the total variance and present initial eigenvalues $3.41,1.82$ and 1.33, respectively. $C_{1}$ is determined by the positive effects of performance orientation, future orientation, institutional collectivism, human orientation and uncertainty avoidance and the negative effects of assertiveness, in-group collectivism and power distance. It is a PC that is shaped by the cultural traits that promote entrepreneurship. $C_{2}$ is positively shaped by performance orientation, institutional collectivism, in-group collectivism, power distance and human orientation, whereas gender egalitarianism and assertiveness have a negative effect. $C_{3}$ is can be characterised as the human

Table 4 Principal component matrix

\begin{tabular}{lllll}
\hline & $\begin{array}{l}\text { Promoting } \\
\text { entrepreneurship PC }\end{array}$ & $\begin{array}{l}\text { Human } \\
\text { orientation PC }\end{array}$ & $\begin{array}{l}\text { Efficiency PC } \\
C_{1}\end{array}$ & $\begin{array}{l}\text { Transaction characteristics } \\
\text { and economic institutions }\end{array}$ \\
\hline $\begin{array}{l}\text { Performance } \\
\text { orientation }\end{array}$ & 0.69 & 0.34 & $C_{3}$ & $\mathrm{Tl}$ \\
$\begin{array}{l}\text { Future orientation } \\
\text { Gender egalitarianism }\end{array}$ & 0.74 & & 0.43 & \\
Assertiveness & -0.32 & -0.62 & -0.52 & \\
Institutional collectivism & 0.75 & -0.31 & 0.73 & \\
In-group collectivism & -0.58 & 0.32 & & \\
Power distance & -0.74 & 0.64 & & \\
Human orientation & 0.30 & 0.31 & & 0.93 \\
Uncertainty avoidance & 0.86 & 0.76 & -0.30 & -0.65 \\
Composite risk & & & & -0.94 \\
Starting a business & & & & 0.59 \\
Corruption perceptions & & & 0.34 \\
index & & & 0.95 \\
Literacy rate & & & & \\
Property rights & & & & \\
Rule of law & & & & \\
\hline
\end{tabular}


oriented cultural characteristic, and is determined by the positive effect of performance orientation, future orientation and assertiveness and the negative effect of gender egalitarianism and human orientation. It expresses the cultural traits of achieving efficiency.

From the variables indicating transaction characteristics and economic institutions characteristics, one PC emerges (TI) that explains $58.86 \%$ of the total variance and presents an initial eigenvalue of 3.53. As can be seen in Table 4, composite risk, literacy rate, property rights and the rule of law shape the promoting effect of TI on opportunity entrepreneurship. On the other hand, the variables indicating the time it takes to start a business and the corruption perception index have a negative effect (as was expected).

Table 4 presents the contents of the PCs, i.e., the variables that affect the PC configuration, which have partial correlation values that are greater than 0.3 .

The following table (Table 5) shows the correlations between the variables used in the basic model. Observing the correlation matrix below, as well as Figures 1 and 2, we are concerned that the opportunity entrepreneurship may be endogenously determined either by the transaction characteristics and economic institutions characteristics component (TI) or the promoting entrepreneurship cultural traits component $\left(C_{1}\right)$. The correlations of the dependent variable with the human-oriented cultural traits component $\left(C_{2}\right)$ and the achieving efficiency cultural traits component $\left(C_{3}\right)$ are quite low and are not expected to have the problem of endogeneity.

Next, we cause a shock in the economies by increasing the values of performance orientation, future orientation, assertiveness and institutional collectivism variables by $30 \%$ and by decreasing the values of uncertainty avoidance variable by $30 \%$ for the countries scoring below the average in each variable separately. In other words, we create the variables $C_{1}{ }^{\prime}, C_{2}{ }^{\prime}$ and $C_{3}{ }^{\prime}$ (Table 6), creating a more opportunity entrepreneurship-oriented world.

Table 7 presents the empirical results of the estimated regressions. The first column shows the estimated basic model (Regression 1). It presents the effect of cultural traits, transaction characteristics and economic institution characteristics on opportunity entrepreneurship. An improvement of $C_{1}$ and TI would have a positive effect on opportunity entrepreneurship (as can be seen in Figures 1 and 2), as these show positive and statistically significant estimates. In contrast, an improved $C_{3}$ would inhibit the opportunity entrepreneurship levels. The formation of TI fully confirms the theoretically expected effect of the variables of the transaction characteristics and the economic institution characteristics on opportunity entrepreneurship. The negative sign of the estimated $C_{3}$ changes its character as regards to its influence on opportunity

Table 5 Correlation matrix

\begin{tabular}{lllllll}
\hline Variable & OPP & TI & $\mathbf{C}_{\mathbf{1}}$ & $\mathbf{C}_{\mathbf{2}}$ & $\mathbf{C}_{\mathbf{3}}$ & Birth \\
\hline $\mathrm{TI}$ & $0.622^{*}$ & & & & & \\
$\mathrm{C}_{1}$ & $0.606^{*}$ & $0.608^{*}$ & & & & \\
$C_{2}$ & -0.213 & $-0.477^{*}$ & 0.034 & & & \\
$C_{3}$ & -0.220 & -0.003 & -0.179 & -0.116 & & \\
Birth & $-0.374^{*}$ & $-0.666^{*}$ & -0.107 & $0.537^{*}$ & -0.081 & \\
PAT & 0.243 & $0.533^{*}$ & $0.487^{*}$ & -0.030 & 0.091 & $-0.502^{*}$ \\
\hline
\end{tabular}

${ }^{*}$ Significance at the $1 \%$ level. 


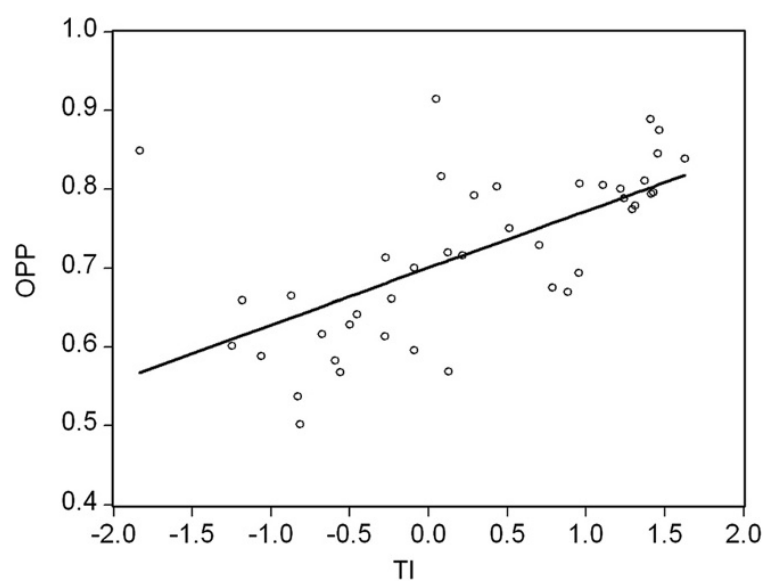

Figure 1 Correlation between opportunity entrepreneurship (OPP) and the transaction characteristics and economic institutions characteristics component (TI). OPP is measured in percentage points. TI is a principal component, and it values is over and below zero.

entrepreneurship. In essence, it becomes human-oriented and becomes less of an efficiency cultural trait component. The adjusted $R^{2}$ of the regression amounts to $43.6 \%$, while according to the F-statistic, the regression is statistically strong.

The second and the third columns of Table 7 show the exogeneity test and the regression results, which determine if the instrumental variables are weak or not. Being concerned that opportunity entrepreneurship is endogenously determined by either TI or $C_{1}$ (see the strong positive correlations in Figures 1 and 2, respectively, and Table 5), we use the Davidson and MacKinnon test $(1989,1993)$ to determine the relationship between OPP and TI and the relationship between OPP and $C_{1}$. To test the hypothesis, we use an instrumental variable that is correlated with the suspect variable (TI or $C_{1}$ ) but not with the error term of the opportunity entrepreneurship equation. The choice of the appropriate instrument is a crucial step.

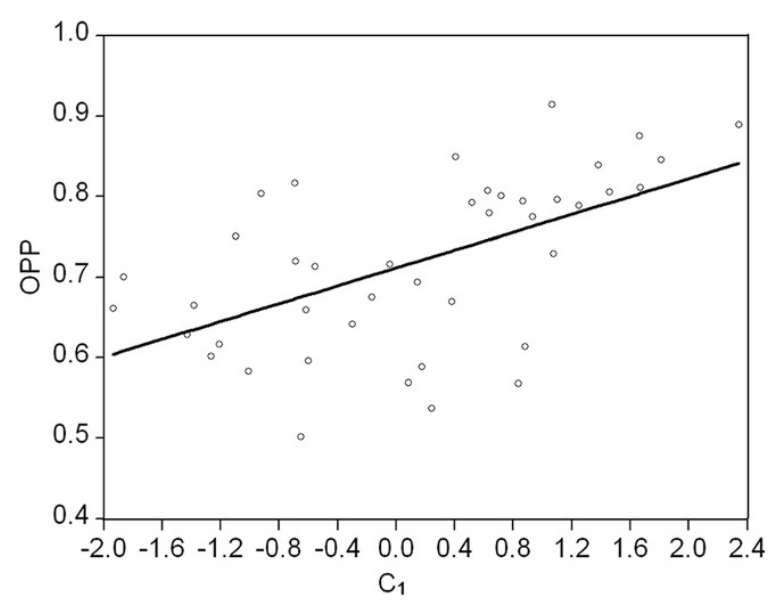

Figure 2 Correlation between opportunity entrepreneurship (OPP) and the promoting entrepreneurship component $\left(\boldsymbol{C}_{1}\right)$. OPP is measured in percentage points. $C_{1}$ is a principal component and its value is over and below zero. 
Table 6 Results of regressions

\begin{tabular}{|c|c|c|c|c|c|}
\hline & $\begin{array}{l}\text { Regression } 1 \\
\text { Basic model }\end{array}$ & $\begin{array}{l}\text { Regression } 2 \\
\text { IV weakness }\end{array}$ & $\begin{array}{l}\text { Regression } 3 \\
\text { IV weakness }\end{array}$ & $\begin{array}{l}\text { Regression } 4 \\
\text { Sensitivity } \\
\text { analysis }\end{array}$ & $\begin{array}{l}\text { Regression } 5 \\
\text { Structural } \\
\text { change }\end{array}$ \\
\hline Dependent variable & OPP & $\mathrm{TI}$ & $\mathrm{C}_{1}$ & OPP & OPP" \\
\hline \multirow[t]{2}{*}{$C_{1}$} & $0.033^{* * *}$ & & & & \\
\hline & $(1.95)$ & & & & \\
\hline \multirow[t]{2}{*}{$C_{2}$} & -0.012 & & & & \\
\hline & $(-0.72)$ & & & & \\
\hline \multirow[t]{2}{*}{$C_{3}$} & $-0.021^{* * *}$ & & & & \\
\hline & $(-1.70)$ & & & & \\
\hline \multirow[t]{2}{*}{$\mathrm{TI}$} & $0.044^{* * *}$ & & & $0.050^{*}$ & \\
\hline & $(1.93)$ & & & $(2.60)$ & \\
\hline \multirow[t]{2}{*}{ Birth } & & $-0.098^{*}$ & & & \\
\hline & & $(-7.84)$ & & & \\
\hline \multirow[t]{2}{*}{ PAT } & & & $0.365^{*}$ & & \\
\hline & & & $(4.21)$ & & \\
\hline \multirow[t]{2}{*}{$C_{1}{ }^{\prime}$} & & & & -0.014 & \\
\hline & & & & $(-0.80)$ & \\
\hline \multirow[t]{2}{*}{$C_{2}^{\prime}$} & & & & $-0.035^{*}$ & \\
\hline & & & & $(-2.73)$ & \\
\hline \multirow[t]{2}{*}{$C_{3}^{\prime}$} & & & & 0.018 & \\
\hline & & & & $(1.25)$ & \\
\hline \multirow[t]{2}{*}{ dum $\times C_{1}^{\prime \prime}$} & & & & & $-0.048^{* *}$ \\
\hline & & & & & $(-1.96)$ \\
\hline \multirow[t]{2}{*}{ dum $\times C_{2}^{\prime \prime}$} & & & & & -0.022 \\
\hline & & & & & $(-1.04)$ \\
\hline \multirow[t]{2}{*}{ dum $\times C_{3}^{\prime \prime}$} & & & & & $0.039^{* *}$ \\
\hline & & & & & $(2.06)$ \\
\hline \multirow[t]{2}{*}{ dum $\times \mathrm{Tl}$} & & & & & 0.007 \\
\hline & & & & & $(0.242)$ \\
\hline \multirow[t]{2}{*}{ Constant } & $0.699^{*}$ & $1.576^{*}$ & $-0.680^{*}$ & $0.702^{*}$ & \\
\hline & $(53.57)$ & $(7.12)$ & $(-3.38)$ & $(54.26)$ & \\
\hline Adjusted $R^{2}$ & 0.43 & & & 0.45 & 0.44 \\
\hline Exogeneity test & & 0.85 & 0.92 & & \\
\hline Partial instrumental variables $R^{2}$ & & 0.54 & 0.26 & & \\
\hline Partial F-statistic & & 61.54 & 17.77 & & \\
\hline
\end{tabular}

*Significant at 1\%; **significant at 5\%; **significant at 10\%. The parentheses include the $t$ test statistics for the coefficients of the regressions. In Regression 5, we also used the variables $C_{1}{ }^{\prime \prime}, C_{2}{ }^{\prime \prime}, C_{3}{ }^{\prime \prime}, T$ " ${ }^{\prime \prime}$ and the constant but do not display their estimates because they are the same as in Regression 1 (the basic model).

According to Regression 2 in Table 6, the birth rate variable can be considered to be exogenous to opportunity entrepreneurship when testing for possible endogeneity with TI through the test of Davidson and MacKinnon $(1989,1993)$. It is believed that it is a strong instrumental variable because it is estimated to have a partial F-statistic of 61.54 (F-statistic must be $>10$ ). According to the partial $\mathrm{R}^{2}, 54 \%$ of the squared residuals are explained by this instrumental variable. Moreover, according to the correlation matrix (Table 5), the birth rate variable appears to be strongly associated with the TI and not 
with the OPP. Simultaneously, it should be noted that based on the regression of the birth rate variable on the OPP, the partial F-statistic is estimated at 7.60 (F-stat $<10)$ and the partial $\mathrm{R}^{2}$ measurement is $16 \%$; hence, the birth rate can be regarded as being exogenous to the OPP. To implement the exogeneity test, we run two OLS regressions. First, we regress the TI on all exogenous variables and instruments and retrieve the residuals. Second, we re-estimate the basic model and include the residuals from the first regression as additional regressors. As a result, the first stage residuals are not statistically different from zero. In a similar manner, according to Regression 3 in Table 7, the variable expressing the number of patents in the economies is exogenous to opportunity entrepreneurship when testing for possible endogeneity with $C_{1}$. It shows a partial F-statistic 17.77 (F-statistic $>10$ ), while the partial $R^{2}$ is $26 \%$. The instrumental variable is also found to be strong after observing the correlation matrix (Table 5). Furthermore, the patents variable appears to be strongly associated with $C_{1}$ and not with the OPP. Simultaneously, it is noted that, based on the regression of the number of patents variable on OPP, the partial F-statistic is estimated at 3.41 (F-stat $<10$ ) and the partial $R^{2}$ is equal to $8 \%$ thus, it is regarded as exogenous to OPP.

However, the values of the exogeneity tests, 0.85 and 0.92 , suggest that the results in Regression 1 (Table 6) are not influenced by endogeneity between opportunity entrepreneurship and TI or $C_{1}$. The estimations for the basic model, presented in Regression 1 , are consistent and unbiased. These results come into agreement with our point of view that in the medium (and short) run, cultural traits, institution settings and transaction characteristics are exogenous to the opportunity entrepreneurship.

The results of the sensitivity analysis shock are presented in Table 6 (Regression 4). Through the sensitivity analysis, we create the variables $C_{1}{ }^{\prime \prime}, C_{2}{ }^{\prime \prime}$ and $C_{3}{ }^{\prime \prime}$ (i.e. the difference between the basic scenario and the case of sensitivity analysis), which arise as values of $C_{1}, C_{2}$ and $C_{3}$ for group 1 and $C_{1}{ }^{\prime}, C_{2}{ }^{\prime}$ and $C_{3}{ }^{\prime}$ for group 2, respectively. The dependent variable OPP is now called OPP"', and its values for group 1 are repeated for group 2 . The same procedure is also implemented for the $\mathrm{PC}$ configured by the transaction characteristics and economic institutions characteristics variables (TI), whose values do not differ between the basic scenario and the case of the sensitivity analysis (TI*). Subsequently, a dummy variable is created whose value is 0 for group 1 and 1 for group 2. Table 6 presents the variables dum $\times C_{1}{ }^{\prime \prime}$, dum $\times C_{2}{ }^{\prime \prime}$, dum $\times C_{3}{ }^{\prime \prime}$ and dum $\times \mathrm{TI}^{*}$, which are the product of the created dummy variable and the variables $C_{1}{ }^{\prime \prime}, C_{2}{ }^{\prime \prime}, C_{3}{ }^{\prime \prime}$ and $\mathrm{TI}^{*}$, respectively.

Table 7 Principal component matrix after the sensitivity analysis

\begin{tabular}{llll}
\hline & $\begin{array}{l}\text { Human orientation PC } \\
\boldsymbol{C}_{\mathbf{1}}{ }^{\prime}\end{array}$ & $\begin{array}{l}\text { Performance orientation PC } \\
\boldsymbol{C}_{\mathbf{2}}{ }^{\prime}\end{array}$ & $\begin{array}{l}\text { Future orientation PC } \\
\mathbf{C}_{\mathbf{3}}{ }^{\prime}\end{array}$ \\
\hline $\begin{array}{l}\text { Performance orientation } \\
\text { Future orientation }\end{array}$ & 0.71 & 0.82 \\
Gender egalitarianism & -0.56 & & \\
Assertiveness & 0.51 & -0.59 & 0.56 \\
Institutional collectivism & & & \\
In-group collectivism & 0.81 & & \\
Power distance & 0.66 & 0.53 & \\
Human orientation & 0.46 & -0.65 & 0.50 \\
Uncertainty avoidance & & & \\
\hline
\end{tabular}


The shock in the economies, through the experiment of the more opportunity entrepreneurship-oriented world, produced two statistically significant structural differences (Table 6, Regression 4). More specifically, for $C_{1}$ and $C_{3}$, the results indicate a marginally significant statistical difference. The variables that configure the TI were not changed; thus, it does not present a statistical difference. The variables that reflect transaction characteristics and economic institutions characteristic did not change during the sensitivity analysis, as no statistically significant structural changes were shown after controls of structural changes with various improvement combinations of the variables that reflect the transaction characteristics and economic institutions characteristics.

Under the new prevailing conditions, the statistical significance of the humanoriented cultural traits component $\left(\mathrm{C}_{1}{ }^{\prime}\right)$ and the future-oriented cultural traits component $\left(\mathrm{C}_{3}{ }^{\prime}\right)$ is lost when considering their impact on the variable of opportunity entrepreneurship. Unlike in the basic model, only the principal component, $\mathrm{C}_{2}{ }^{\prime}$, is statistically significant at a level of $1 \%$ with respect to variables that reflect the cultural traits, and its growth is expected to adversely affect opportunity entrepreneurship. $\mathrm{C}_{2}$ ' is now positively shaped by performance orientation and power distance, whereas assertiveness and human orientation have a negative effect. Therefore, $\mathrm{C}_{2}{ }^{\prime}$ can be described as a performance-oriented cultural characteristic component (Table 7). Because it was not influenced by the sensitivity analysis and because opportunity entrepreneurship continues to respond positively to improvements in the transaction characteristics and economic institutions characteristics, the transaction characteristics and economic institutions characteristics component (TI) remains statistically significant at a level of $1 \%$, as was expected. The adjusted $R^{2}$ of the regression equals $44.8 \%$, while according to the F-statistic, the regression is statistically strong.

The results of sensitivity analysis highlight the usefulness of the variables we use as basic and critical factors in shaping opportunity entrepreneurship. If there was a timeless way to shape a promoting opportunity entrepreneurship background, then there would not be reasons to worry about the cultural traits anymore and any improvement on that would not have any more pushing up effects on opportunity entrepreneurship. Thus, the cultural traits are crucial only for earlier stages of opportunity entrepreneurship development.

On the contrary, our findings pinpoint that there is always a reason of institution improvement irrespectively of the cultural traits status, in order to improve opportunity entrepreneurship. This conclusion is quite interesting since it separates the policy effects on the cultural traits (and the policies applied to it - education, political stability, knowledge improvement, etc.) versus the effects from policies applied on the institution framework.

In total and after the sensitivity analysis, the following table (Table 8) presents the results on the satisfaction of the hypotheses presented. The table presented is divided into two parts; one for the basic model and one for the sensitivity analysis.

Hypothesis 1 is partially satisfied in both basic model and sensitivity analysis. In the basic model, through the promoting entrepreneurship PC $\left(C_{1}\right)$, all variables seem to affect opportunity entrepreneurship satisfying hypothesis 1 , except from the assertiveness and uncertainty avoidance of the societies. In respect of the efficiency $\mathrm{PC}\left(C_{3}\right)$, only gender egalitarianism and human orientation satisfy hypothesis 1 . After the 
sensitivity analysis, through the influence of the performance orientation $\mathrm{PC}\left(C_{2}^{\prime}\right)$ on opportunity entrepreneurship, all variables except from performance orientation satisfy hypothesis 1 . However, obviously, there is a significant relationship between cultural traits of the societies and opportunity entrepreneurship levels. Hypotheses 2 and 3 are fully satisfied in both the basic model and the sensitivity analysis. Opportunity entrepreneurship levels have a significant relationship with transaction costs in the economic relationships and economic institutions in the societies.

\section{Conclusions}

The paper examines the formation of opportunity entrepreneurship by dividing the examined forces into two groups: (1) the cultural traits and (2) the transaction and economic institutions characteristics. After the empirical analysis, we conclude that those group's effects can be regarded as exogenous to opportunity entrepreneurship in the medium-term, and there are some significant relationships derived.

The cultural traits of the societies significantly shape opportunity entrepreneurship levels. The nature of the PCs indicates that the cultural traits may positively or negatively affect opportunity entrepreneurship: the promoting entrepreneurship cultural traits component $\left(C_{1}\right)$ seems to influence it positively, while the achieving efficiency cultural traits component $\left(C_{3}\right)$ reveals the negative side of the same cultural dimensions, vis-à-vis their impact on opportunity entrepreneurship. Simultaneously, the relationship between the transaction characteristics and the economic institution characteristics component (TI) with opportunity entrepreneurship fully confirms that the expected results based on the theory, low levels of overall risk, less time needed to start new businesses, low corruption, high literacy levels, property rights protection and the rule of law, are conditions conducive to opportunity entrepreneurship, thus creating new business opportunities.

In the hypothesis of the existence of a more opportunity entrepreneurship-oriented world, we observe that the cultural traits inhibit businesses. The effect of this shock (sensitivity analysis) in the examined societies is extensive. The culture of the societies seems to be geared more towards humans and not towards performance. Power inequalities and the assertiveness of society members decrease the number of possible business opportunities. Under these circumstances, the promotion of entrepreneurship is no longer dependent on the cultural traits, which presents 'entrepreneurial maturity', but on the transaction and economic institutions characteristics.

Table 8 The hypotheses results

\begin{tabular}{|c|c|c|c|}
\hline & Not satisfied & Partial satisfied & Satisfied \\
\hline \multicolumn{4}{|l|}{ Basic model } \\
\hline Hypothesis 1 & & $x$ & \\
\hline Hypothesis 2 & & & $x$ \\
\hline Hypothesis 3 & & & $x$ \\
\hline \multicolumn{4}{|c|}{ Sensitivity analysis } \\
\hline Hypothesis 1 & & $x$ & \\
\hline Hypothesis 2 & & & $x$ \\
\hline Hypothesis 3 & & & $x$ \\
\hline
\end{tabular}


The present paper's findings have particularly important implications that impact on economic policy issues in the societies. It turns out that there is some significant influence on critical variables of the economy, such as opportunity entrepreneurship, which has medium-term character regarding its time impact on economic activity, cultural traits and transaction characteristics and the economic institutions characteristics effects on opportunity entrepreneurship. Also, it seems that investments and interventions in these two areas can have medium-term significant impact on opportunity entrepreneurship. Furthermore, from the findings in the entrepreneurship literature, it appears that opportunity entrepreneurship is extremely difficult to influence, and therefore the fact that the present paper demonstrates some canal effects is fascinating. In addition, the present paper demonstrates that the wider social and political environment might affect opportunity entrepreneurship. For example, the level of risk and uncertainty in the economy can be considered as a productive factor in shaping the economic conditions that affect opportunity entrepreneurship. Lastly, the implications provided by the present paper extend further to areas which are intuitively considered as important but have not been quantified and examined, so far, for their sensitivity results on the crucial parameters.

Policy implications can be on two dimensions; (a) investments in education to improve cultural traits and (b) lessening transaction costs and institutional reorganisation to improve economic institutions, related to opportunity entrepreneurship.

Investments in the quality and on quantitative issues of education are the basic way of intervention to enhance the cultural traits of the societies. Through increases of productivity, education brings about social and economic attributes that enhance opportunity entrepreneurship levels. Such investments could be interventions on years of schooling, levels of attainment and on direction of studies and training fields. Through investments in education, societies can have a stock of opportunity entrepreneurs that have acquired the necessary skills to develop new technologies themselves or to adopt and use foreign technology (Fossen and Buttner 2012). Opportunity entrepreneurs can be prepared more productively to take decisions waiting for the optimal time.

Economic policies on lessening transaction costs could have significant benefits on opportunity entrepreneurship levels too. Thus, reducing bureaucracy in the economies e.g. through simplifying regulations and application procedures would require less time to start a new business. Achieving stability in political, economic and financial level would be related with lower levels of composite risk. Achieving economic and social progress, democratic values and strong civil society could lower the corruption in societies. Investments in education would imply higher literacy levels and thus less costs in economic transactions. Lastly, institutional reorganisation through better legal protection on property rights and clear laws that are fully enforced by the state, and through better formation and implementation of law, dispute settlement and people's access, and use of state legal systems would enhance opportunity entrepreneurship.

A shortcoming of the present paper is the small sample of countries available, which leads to limited degrees of freedom. This limitation is the result of a lack of extensive data on the variables related to opportunity entrepreneurship. Furthermore, the sample was reduced in an effort to find common data among many countries for the variables used. Finally, one may think that the data are not all from the same period of time, but all data in the basic model concern averages of the period 1995-2006, 1996-2006 or 
2001-2006. Only cultural traits refer to the period 1995-1997, but we consider cultural traits as long lasting in character due to the fact that cultural values present stability through time.

The present paper may be further extended by comparing its findings with an analysis estimating the effects of the same independent variables on the necessity-driven entrepreneurship, in order to investigate the characteristics of the societies and the economies that lead to necessity/opportunity motivational categories. In addition, further research may provide entrepreneurial policies, analysing the contribution of transactions, institutions and culture in the development of entrepreneurship, or it could include other characteristics of societies and economies that can affect entrepreneurship levels (institutional trust, interpersonal trust, knowledge, etc.). Lastly, concerning the sensitivity analysis, maybe different cases could be used in order to see what happens not only when the world is more opportunity entrepreneurship-oriented but also what happens when it is less opportunity entrepreneurship-oriented.

Competing interest

The author(s) declare that they have no competing interests.

\section{Authors' contribution}

PP and PK carried out all the work presented in this manuscript jointly. Both authors read and approved the final manuscript.

Received: 7 February 2014 Accepted: 17 June 2014

Published online: 17 September 2014

\section{References}

Abdi, H, \& Williams, LJ. (2010). Principal component analysis. Wiley Interdisciplinary Reviews: Computational Statistics.

Acemoglu, D. (2009). Introduction to modern economic growth. Massachusetts Institute of Technology: Department of Economics.

Acemoglu, D, Johnson, S, \& Robinson, JA. (2001). The colonial origins of comparative development: an empirical investigation. American Economic Review, 91, 1369-1401.

Acs, ZJ, Desai, S, \& Hessels, J. (2008). Entrepreneurship, economic development and institutions. Small Business Economics, 31, 219-234. doi:10.1007/s11187-008-9135-9.

Acs, ZJ, Braunerhjelm, P, Audretsch, DB, \& Carlsson, B. (2009). The knowledge spillover theory of entrepreneurship. Small Business Economics, 32(1), 15-30.

Audretsch, DB. (2007). The entrepreneurial society. New York: Oxford University Press.

Baumol, WJ. (1990). Entrepreneurship: productive, unproductive and destructive. Journal of Political Economy, 98, 893-921.

Bos, JWB, Economidou, C, Koetter, M, \& Kolari, JW. (2010). Do all countries grow alike? Journal of Development Economics, 91(1), 113-127.

Boyer, P, \& Petersen, M. (2012). The naturalness of (many) social institutions: evolved cognition as their foundation. Journal of Institutional economics, 8(1), 1-25.

Chen, C, Peng, MW, \& Saparito, PA. (2002). Individualism, collectivism, and opportunism: a cultural perspective on transaction cost economics. Journal of Management, 28(4), 567-583.

Cleveland, M, \& Laroche, M. (2007). Acculturation to the global consumer culture: scale development and research paradigm. Journal of Business Research, 60(3), 249-260.

Companys, YE, \& McMullen, JS. (2007). Strategic entrepreneurs at work the nature. Discovery, and Exploitation of Entrepreneurial Opportunities, Small Business Economics, 28, 301-322.

Conway, LG, \& Schaller, M. (2007). How communication shapes culture. In K Fiedler (Ed.), Frontiers of social psychology: social communication (pp. 107-127). New York: Psychology Press.

Davidson, R, \& MacKinnon, JG. (1989). Testing for consistency using artificial regressions. Economic Theory, 5, 363-384.

Davidson, R, \& MacKinnon, JG. (1993). Estimation and inference in econometrics. New York: Oxford University Press.

Del Giudice, M, Della Peruta, MR, \& Maggioni, V. (2013). Spontaneous processes of reproduction of family-based entrepreneurship: an empirical research on the cognitive nature of the spin-offs. Journal of Innovation and Entrepreneurship, 2, 12. doi:10.1186/2192-5372-2-12.

Douglas, M. (1987). How institutions think. New York: Syracuse University Press.

Fossen, FM, \& Buttner, TJM. (2012). The returns to education for opportunity entrepreneurs, necessity entrepreneurs, and paid employees. Discussion Paper: Freie University of Berlin, School of Business and Economics.

Freytag, A, \& Thurik, R. (2007). Entrepreneurship and its determinants in a cross country setting. Journal of Evolutionary Economics, 17, 117-131.

Fukuyama, F. (2001). Culture and economic development: cultural concerns. In NJ Smelser \& PB Baltes (Eds.), International encyclopedia of the social and behavioral sciences (pp. 3130-3134). Oxford, England: Elsevier Internet publication. 
Ghoshal, S, \& Moran, P. (1996). Bad for practice: a critique of the transaction cost theory. Academy of Management Review, 21, 13-47.

Granovetter, MS. (1985). Economic action and social structure: the problem of embeddedness. American Journal of Sociology, 91(3), 481-510.

Greif, A. (1994). Cultural beliefs and the organization of society: a historical and theoretical reflection on collectivist and individualist societies. Political Economy, University of Chicago Press, 102, 912-50.

Hausman, JA. (1978). Specification tests in econometrics. Econometrica, 46, 1251-1271.

Hodgson, GM. (1988). Economics and institutions: a manifesto for a modern institutional economics. Cambridge and Philadelphia: Polity Press and University of Pennsylvania Press.

Hofstede, G. (1980). Culture's consequences: international differences in work-related values. CA: Sage Publ., Beverly Hills. Hofstede, G, Hofstede, GJ, \& Minkov, M. (2010). Cultures and Organizations: Software of the Mind (3rd ed.). McGraw-Hill USA. Hong, Y. (2009). A dynamic constructivist approach to culture: moving from describing culture to explaining culture. In RS Wyer, CY Chiu, \& YY Hong (Eds.), Understanding culture: theory, research and application. New York: Psychology Press.

House, RJ, Hanges, PJ, Javidan, M, Dorfman, PW, \& Gupta, V. (2004). Culture, leadership and organisations - the GLOBE study of 62 societies. Thousand Oaks, CA: Sage Publications.

Johnston, L. (1996). Resisting change: information-seeking and stereotype change. European Journal of Social Psychology, $26,799-825$.

Jonsson, PO. (2001). Networks, culture, transaction costs and discrimination. International Journal of Social Economics, 28, 942-958. No. 10/11/12.

Karlsson, C, \& Acs, ZJ. (2002). Introduction to institutions, entrepreneurship and firm growth: the case of Sweden. Small Business Economics, 19(2), 63-67.

Karlsson, C, \& Karlsson, M. (2002). Economic policy, institutions and entrepreneurship. Small Business Economics, 19(2), 163-171.

Knight, FH. (1971). Risk, uncertainly, and profit. Chicago, IL: The University of Chicago Press. Originally published in 1921 by Houghton Mifflin Company.

Kreiser, PM, Marino, LD, Kuratko, DF, \& Weaver, KM. (2013). Disaggregating entrepreneurial orientation: the non-linear impact of innovativeness, proactiveness and risk-taking on SME performance. Small Business Economics, 40(2), 273-291.

Lingas, K. (2013). Family businesses and the gender of entrepreneurship. Journal of Innovation and Entrepreneurship, 2, 4. doi:10.1186/2192-5372-2-4.

Machiavelli, N. (1987). Discourses on Livy. New York: Oxford University Press. 1519.

Marshall, A. (1997). Principles of economics. New York: Prometheus Books. 1890.

Marsili, O. (2002). Technological regimes and sources of entrepreneurship. Small Business Economics, 19(3), 217-231.

Mesoudi, A. (2011). Cultural evolution: how Darwinian theory can explain human culture and synthesize the social sciences. Chicago, IL: University of Chicago Press.

Montesquieu, MC. (1989). The spirit of the laws. In AM Cohler, M Basia Carolyn, \& S Harold Samuel (Eds.), (p. 1748). New York: Cambridge University Press.

Mueller, P. (2007). Exploiting entrepreneurial opportunities: the impact of entrepreneurship on growth. Small Business Economics, 28(4), 355-362.

North, DC. (1990). Institutions, institutional change and economic performance. Cambridge: Cambridge University Press.

Petrakis, PE. (1997). Entrepreneurship and growth: creative and equilibrating events. Small Business Economics, 9(5), 383-402.

Petrakis, PE. (2004). Entrepreneurship and risk premium. Small Business Economics, 23(2), 85-98.

Petrakis, PE, \& Kostis, PC. (2013a). Economic growth and cultural change. Journal of Socio-Economics. doi:10.1016/j. socec.2013.02.011

Petrakis, PE, \& Kostis, PC. (2013b). The effects of cultural background, and knowledge creation and impact on self-employment and entry density rates, review of economics and finance, 3(2).

Petrakis, PE, \& Valsamis, DG. (2013). Entrepreneurship, transaction costs and cultural background, international business research, 6(5).

Pinillos, MJ, \& Reyes, L. (2011). Relationship between individualist-collectivist culture and entrepreneurial activity: evidence from global entrepreneurship monitor data. Small Business Economics, 37(1), 23-37.

Reynolds, P, Bygrave, W, Autio, E, \& Hay, M. (2002). Global entrepreneurship monitor; executive report. Wellesley, MA: Babson College, Kauffman Foundation and London Business School.

Richerson, PJ, \& Boyd, R. (2005). Not by genes alone: how culture transformed human evolution. Chicago, IL: University of Chicago Press.

Rozin, P. (2010). Evolutionary and cultural psychology: complementing each other in the study of culture and cultural evolution. In M Schaller, A Norenzayan, SJ Heine, T Yamagishi, \& T Kameda (Eds.), Evolution, culture, and the human mind (pp. 9-22). New York: Psychology Press.

Salamouris, IS. (2013). How overconfidence influences entrepreneurship. Journal of Innovation and Entrepreneurship, 2, 8. doi:10.1186/2192-5372-2-8.

Sarasvathy, SD, Dew, N, Velamuri, SR, \& Venkatamaran, S. (2003). Three views of entrepreneurial opportunity. In ZJ Acs \& DB Audretsch (Eds.), Handbook of entrepreneurship research (pp. 141-160). Boston: Kluwer.

Schumpeter, J. (1934). The theory of economic development. Cambridge, Massachusetts: Harvard University Press.

Schumpeter, J. (1950). Capitalism, socialism and democracy. New York: Harper and Row.

Schwatrz, SH. (2009). Culture matters: national value cultures, sources and consequences. In RS Wyer, CY Chiu, \& YY Hong (Eds.), Understanding culture: theory, research and application (pp. 127-150). New York: Psychology Press.

Shane, SA. (1992). Why do some societies invent more than others? Journal of Business Venturing, 7, 29-46.

Shane, S. (2003). A general theory of entrepreneurship - the individual-opportunity Nexus. UK: Edward Elgar.

Shane, S, \& Venkataraman, S. (2000). The promise of entrepreneurship as a field of research. Academy of Management Review, 25(1), 218-228

Shlens, J. (2009). A tutorial on principal component analysis. http://www.cs.uu.nl/docs/vakken/ddm/texts/Normal/pca.pdf.

Smith. (2002). Tutorial on principal components analysis. http://www.cs.otago.ac.nz/cosc453/student_tutorials/ principal_components.pdf. 
Spolaore, E, \& Wacziarg, R. (2013). How deep are the roots of economic development? Journal of Economic Literature, $51(2), 1-45$.

Spulber, DF. (2008). The economic role of the entrepreneur. http://lawlab.org/EconomicRoleoftheEntrepreneur.pdf.

Stuetzer, M, Obschonka, M, Brixy, U, Sternberg, R, \& Cantner, U. (2013). Regional characteristics, opportunity perception and entrepreneurial activities. Small Business Economics. doi:10.1007/s11187-013-9488-6.

Swierczek, FW, \& Ha, TT. (2003). Entrepreneurial orientation, uncertainty avoidance and firm performance: An analysis of Thai and Vietnamese SMEs (pp. 46-58).: Entrepreneurship and Innovation.

Throsby, D. (2001). Economics and culture. Cambridge: Cambridge University Press.

Tominc, P, \& Rebernik, M. (2007). Growth aspirations and cultural support for entrepreneurship: a comparison of post-socialist countries. Small Business Economics, 28(2-3), 239-255.

Uzunidis, D, Boutillier, S, \& Laperche, B. (2014). The entrepreneur's 'resource potential' and the organic square of entrepreneurship: definition and application to the French case. Journal of Innovation and Entrepreneurship, 3, 1. doi:10.1186/2192-5372-3-1.

Wennekers, ARM, Uhlaner, L, \& Thurik, AR. (2002). Entrepreneurship and its conditions: a macro perspective. International Journal of Entrepreneurship Education, I(1), 25-64.

doi:10.1186/s13731-014-0011-3

Cite this article as: Petrakis and Kostis: Medium term effects of culture, transactions and institutions on opportunity entrepreneurship. Journal of Innovation and Entrepreneurship 2014 3:11.

Submit your manuscript to a SpringerOpen ${ }^{\circ}$ journal and benefit from:

- Convenient online submission

- Rigorous peer review

- Immediate publication on acceptance

- Open access: articles freely available online

- High visibility within the field

Retaining the copyright to your article

Submit your next manuscript at $\gg$ springeropen.com 